\title{
PENGARUH KECEPATAN COMBINE HARVESTER PADA RODA SEBELAH DALAM DAN LUAR TERHADAP PEMADATAN TANAH PADA SAAT PEMBELOKAN
}

\section{(The effect of The Speed of The Combine Harvester on The Inner and Outer Wheels on Compaction of The Soil During Bending)}

\author{
St. Munawarah Muluk ${ }^{1 *}$, Suhardi ${ }^{2)}$, dan Sitti Nur Faridah ${ }^{3)}$ \\ ${ }^{1)}$ Program Studi Teknik Pertanian, Universitas Hasanuddin, Makassar \\ ${ }^{2)}$ Program Studi Teknik Pertanian, Universitas Hasanuddin, Makassar \\ ${ }^{3)}$ Program Studi Teknik Pertanian, Universitas Hasanuddin, Makassar \\ *) Email korespondensi: Munawarahmuluk92@gmail.com
}

\begin{abstract}
ABSTRAK
Pemadatan tanah adalah perubahan keadaan dimana terjadi penyusutan volume tanah atau terjadi kenaikan berat tanah pada satu satuan volume tertentu. Pemadatan tanah dipengaruhi oleh besar kecilnya energi pemadatan yang diberikan, seperti penggunaan combine harvester. Pada saat pemanenan akan memberikan dampak negatif berupa terjadinya perubahan sifat fisik dan mekanik tanah. Tujuan dari penelitian ini adalah untuk mengetahui pengaruh lintasan combine harvester terhadap pemadatan tanah serta mengetahui pengaruh kecepatan combine harvester pada roda sebelah dalam dan luar terhadap pemadatan tanah yang terjadi. Metode yang digunakan adalah mengambil sampel tanah sebelum dan setelah dilintasi combine harvester dalam proses pemanenan tanaman padi (Oryza sativa L.). Sampel dianalisis untuk mengetahui nilai kadar air tanah, bulk density, partikel density, dan porositas. Parameter tersebut digunakan untuk mengetahui nilai pemadatan tanah yang terjadi pada saat pembelokan. Berdasarkan hasil penelitian maka dapat disimpulkan bahwa lintasan dalam proses pembelokan mengakibatkan terjadinya perbedaan nilai bulk density pada roda sebelah dalam dan luar. Hal ini disebabkan pengaruh tekanan pada roda sebelah dalam lebih besar dibandingkan pada roda sebelah luar. Perbedaan terjadi karena jarak tempuh pada roda sebelah luar lebih jauh dibandingkan pada roda sebelah dalam, sehingga kecepatan pada roda sebelah luar lebih besar dibandingkan pada roda sebelah dalam. Hal ini disebabkan combine harvester berputar pada arah kanan maka titik kuat alat cenderung pada roda sebelah dalam.
\end{abstract}

Kata Kunci: Combine Harvester, Bulk Density, Pemadatan Tanah, Roda dan Kecepatan

\section{PENDAHULUAN}

\section{Latar Belakang}

Padi (Oryza sativa L.) merupakan salah satu tanaman yang dibudidayakan secara serentak. Proses pemanenan membutuhkan tenaga kerja yang sangat banyak agar pemanenan dapat dilakukan dengan tepat waktu. Salah satu usaha yang dapat dilakukan untuk mengefisienkan tenaga kerja adalah dengan cara meningkatkan kapasitas dengan menggunakan mesin panen yaitu combine harvester.

Mekanisasi pertanian dengan menggunakan combine harvester sebagai alat pemanenan sudah berlangsung hingga saat ini. Adapun dampak dari penggunaan peralatan mekanis pada lahan pertanian adalah pemadatan tanah. Adapun faktor yang mempengaruhi proses pemadatan tanah yaitu berat dan tekanan dari alat. Selain itu, terdapat faktor lain yang perlu 
dipertimbangkan yaitu intensitas lalu lintas suatu alat.

Pemadatan tanah merupakan perubahan kondisi yang mengakibatkan terjadinya penurunan volume tanah. Pemadatan tanah dipengaruhi oleh besar kecilnya energi pemadatan yang diberikan. Selain itu, didalam tanah terkandung beberapa bahan utama yaitu mineral, bahan organik, air, dan udara. Pemadatan yang berlebihan pada tanah tersebut akan menyebabkan struktur tanah menjadi rusak. Sehingga bahan utama yang terkandung dalam tanah akan terganggu.

Dalam proses pemanenan dengan menggunakan combine harvester hingga saat ini belum diketahui perbedaan pemadatan tanah pada saat alat melintas lurus maupun saat pembelokan. Berdasarkan uraian tersebut maka perlu dilakukan penelitian ini untuk mengetahui perbedaan pengaruh lintasan dan kecepatan combine harvester terhadap pemadatan tanah pada saat pembelokan. Agar kita dapat mengetahui apakah roda sebelah dalam dan luar alat tersebut berpengaruh terhadap pemadatan yang akan terjadi.

\section{Tujuan dan Kegunaan}

Penelitian ini bertujuan untuk mengetahui pengaruh lintasan combine harvester terhadap pemadatan tanah serta mengetahui pengaruh kecepatan combine harvester pada roda sebelah dalam dan luar terhadap pemadatan tanah pada saat pembelokan.

Kegunaan dari penelitian ini adalah sebagai acuan dan informasi kepada petani dan masyarakat umum mengenai pengaruh penggunaan combine harvester terhadap pemadatan tanah pada proses pemanenan.

\section{METODE PENELITIAN}
Alat
Alat yang digunakan pada penelitian ini adalah Combine Harvester Kubota DC- 60 , ring sampel sebanyak 24 buah, mistar, patok, linggis, stopwatch, cawan, timbangan digital, timbangan berat badan, spidol, label, plastik gula, plastik c-tik, plaster bening,

gelas ukur, saringan, pengaduk, sprayer, oven, aluminium foil, kamera, laptop dan alat tulis menulis.

\section{Bahan}

Bahan yang digunakan pada penelitian ini adalah sampel tanah.

\section{Prosedur Penelitian}

Penelitian ini dilakukan pada satu petakan sawah untuk pengoperasian alat dan mengambil sampel tanah untuk menentukan pengaruh lintasan combine harvester terhadap pemadatan tanah pada saat pembelokan. Pengujian ini dilakukan dengan mengambil sampel tanah sebelum dan setelah dilintasi oleh combine harvester.

\section{Pengujian alat combine harvester}

a. Survey lokasi penelitian.

b. Siapkan alat dan bahan yang akan digunakan.

c. Pola pemanenan combine harvester yang akan dilakukan adalah pola keliling tepi, dapat dilihat pada Gambar 3 berikut:

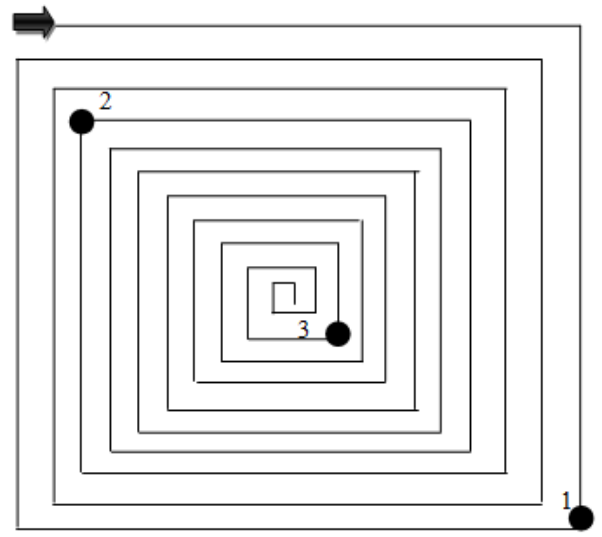

Gambar 3. Pola Keliling Tepi

d. Memberi tanda pada setiap belokan yang akan dilintasi untuk pengambilan sampel tanah.

e. Ambil sampel tanah dengan kedalaman 0-10 $\mathrm{cm}$ dan 10-20 $\mathrm{cm}$ sebelum dilintasi combine harvester untuk menentukan kadar air tanah, tekstur tanah, bulk density, partikel density, dan porositas.

f. Pengoperasian alat. Sebelum alat dioperasikan terlebih dahulu harus diketahui berat alat tersebut lalu ditambahkan dengan berat pengemudi karena akan berpengaruh terhadap pemadatan tanah yang akan terjadi. 
g. Hitung kecepatan yang digunakan pada saat alat pembelokan dengan menggunakan stopwatch dengan menggunakan rumus:

Dimana:

$$
\operatorname{Kecepatan}(v)=\frac{s}{t}
$$

$\mathrm{v}: \operatorname{Kecepatan}(\mathrm{m} / \mathrm{s})$

$\mathrm{s}$ : Jarak (m)

t : Waktu (s)

h. Setelah proses pemanenan selesai maka selanjutnya mengambil sampel tanah dengan kedalaman 0-10 dan 10-20 cm yang telah dilintasi combine harvester untuk menentukan kadar air tanah, tekstur tanah, bulk density, partikel density, dan porositas.

i. Pengolahan data untuk menentukan kadar air tanah, tekstur tanah, bulk density, partikel density, dan porositas.

\section{Pengukuran Tekstur Tanah}

Adapun langkah-langkah yang dilakukan dalam penentuan tekstur tanah menggunakan metode hydrometer yaitu:

a. Timbang 20 gram tanah kering udara, butir-butir tanah ini berukuran kurang dari $2 \mathrm{~mm}$.

b. Masukkan ke dalam erlenmeyer atau botol tekstur dan menambahkan $10 \mathrm{ml}$ calgon $4 \%$ dan air secukupnya.

c. Tutup dengan plastik, kocok dengan mesin pengocok selama 1-2 jam.

d. Tuangkan secara kualitatif semua isinya ke dalam silinder sedimentasi $500 \mathrm{ml}$ yang diatasnya dipasangi saringan dengan diameter lubang sebesar 0.05 $\mathrm{mm}$ dan bersihkan botol tekstur dengan bantuan botol semprot.

e. Semprot dengan sprayer sambil diadukaduk semua suspense yang masih tinggal pada sariagan sehingga semua partilkel debu dan liat telah turun (air saringan telah jernih).

f. Pindahkan pasir yang tertinggal kedalam cawan petri dengan botol semprot kemudian masukkan dalam oven bersuhu $105^{\circ} \mathrm{C}$ selama $2 \times 24$ jam.

g. Masukkan dalam desikator dan timbang hingga berat pasir diketahui (catat sebagai $\mathrm{C}$ gram) h. Encerkan larutan suspense dalam silinder sedimentasi ke dalam pengocok lalu aduk selama 3 menit.

i. Tuangkan kira-kira 3 tetes amyl alcohol ke permukaan suspensi untuk menghilangkan gangguan buih yang mungkin timbul.

j. Setelah 15 detik, masukkan hydrometer ke dalam suspense dengan hati-hati agar suspensi tidak banyak terganggu.

k. Setelah 40 detik, baca dan catat pembacaan hydrometer pertama $\left(\mathrm{H}_{1}\right)$ dan suhu sispansi ( $\left.\mathrm{t}_{1}\right)$ keluarkan hydrometer dari suspensi.

1. Setelah menjelang 8 jam, masukkan hydrometer dan catat pembacaan hydrometer kedua $\left(\mathrm{H}_{2}\right)$ dan suhu sispansi $\left(\mathrm{t}_{2}\right)$.

m. Hitung berat debu dan liat dengan menggunakan persamaan di bawah ini:

Berat debu dan liat $=$

$$
\left[\frac{H 1+0,3(t 1-19,8)}{2}\right]-0,5
$$

Berat liat $\left.=\frac{H 2+0,3(t 2-19,8)}{2}\right]-0,5$

Berat debu $=$ Berat $($ debu + liat $)-$ berat liat (a-c)

n. Hitung persentase pasir, debu dan liat dengan persamaan:

$$
\begin{aligned}
& \% \text { Pasir }=\frac{c}{a+c} \times 100 \% \\
& \% \text { Debu }=\frac{(a-b)}{a+c} \times 100 \% \\
& \% \text { Liat }=\frac{b}{a+c} \times 100 \%
\end{aligned}
$$

o. Masukkan nilai yang didapat ke dalam segitiga tekstur.

\section{Kadar Air Tanah}

Pengukuran kadar air tanah dilakukan dengan metode gravimetri. Pengukuran ini dimulai dengan mengambil sampel tanah dari lapangan, kemudian ditimbang untuk mendapatkan berat basah (Wa), selanjutnya sampel tanah dimasukkan ke dalam oven pada suhu $105^{\circ} \mathrm{C}$ selama 24 jam. Kemudian ditimbang untuk mendapatkan berat kering $(\mathrm{Wb})$. Menghitung kadar air tanah dengan sampel kedalaman 0-10 $\mathrm{cm}$ dan sampel kedalaman 10-20 cm dengan persamaan:

$$
K A=\left(\frac{W a-W b}{W b}\right) \times 100
$$


Dimana:

KA : Kadar air tanah (\%)

Wa : Berat sampel tanah basah (g)

$\mathrm{Wb}$ : Berat sampel tanah kering $(\mathrm{g})$

\section{Bulk Density Tanah}

Bulk Density atau bobot isi tanah dapat dihitung menggunakan metode ring sampel yaitu dengan mengambil sampel tanah pada setiap titik kedalaman 0-10 $\mathrm{cm}$ dan kedalaman 10-20 cm dengan persamaan:

Dimana:

$$
B D=\frac{B k}{V t}
$$

$\mathrm{BD}:$ Bulk density $\left(\mathrm{g} / \mathrm{cm}^{3}\right)$

Bk : Berat kering $(\mathrm{g})$

$\mathrm{Vt}$ : Volume tanah $\left(\mathrm{cm}^{3}\right)$

\section{Partikel Density}

Partikel density dapat dihitung dengan mengambil sampel tanah hasil analisa bulk density yang telah dihancurkan sebanyak 20 gram, lalu memasukkan ke dalam gelas ukur $50 \mathrm{ml}$ lalu diisi air sebanyak $30 \mathrm{ml}$ dan diaduk untuk menghomogenkan air (partikel) dengan persamaan:

Dimana:

$$
P D=\frac{B k}{V p t}
$$

PD : Partikel density $\left(\mathrm{g} / \mathrm{cm}^{3}\right)$

$\mathrm{Bk}$ : Berat kering $(\mathrm{g})$

Vpt : Volume partikel tanah $\left(\mathrm{cm}^{3}\right)$

\section{Porositas}

Porositas merupakan total pori yang ada di dalam tanah yaitu ruang dalam tanah yang ditempati oleh air dan udara yang dapat dihitung menggunakan persamaan:

Dimana:

$$
P=\left(1-\frac{B D}{P D}\right) \times 100 \%
$$

$\mathrm{P} \quad$ : Porositas (\%)

BD : Bulk density $\left(\mathrm{g} / \mathrm{cm}^{3}\right)$

PD : Partikel density $\left(\mathrm{g} / \mathrm{cm}^{3}\right)$

\section{HASIL DAN PEMBAHASAN}

\section{Tekstur Tanah}

Lahan tempat penelitian yang digunakan merupakan areal lahan persawahan dengan permukaan datar yang ditanami tanaman padi. Tanah pada area penelitian merupakan jenis tanah liat. Tabel 1 menunjukkan kandungan unsur-unsur yang terdapat pada tanah pada lokasi penelitian.

Tabel 1. Unsur Kandungan Tanah pada Area Persawahan Tanaman Padi Kab. Wajo

\begin{tabular}{cccccc}
\hline \multirow{2}{*}{ No } & \multirow{2}{*}{ Sampel } & Pasir & Debu & Liat & Klas \\
\cline { 3 - 5 } & & & \% & & Tekstur \\
\hline 1 & Titik 1 & 6 & 35 & 59 & Liat \\
2 & Titik 2 & 9 & 40 & 51 & Liat \\
3 & Titik 3 & 8 & 37 & 55 & Liat \\
\hline
\end{tabular}

Berdasarkan hasil uji laboratorium perbandingan liat, debu dan pasir dapat diketahui bahwa tanah tersebut merupakan tanah yang bertekstur liat. Tanah dengan tekstur liat mempunyai kemampuan menahan air yang baik. Material tanah liat mempunyai daya serap yang baik terhadap perubahan kadar kelembapan karena tanah liat mempunyai luas permukaan yang besar. Tekstur tanahnya cenderung lengket bila dalam keadaan basah dan kuat menyatu antara butiran tanah yang satu dengan lainnya. Hal ini sesuai dengan pendapat Hardjowigeno (2007) yang menyatakan bahwa tanah dengan tekstur liat mempunyai luas permukaan yang lebih besar sehingga kemampuan menahan air yang tinggi. Berdasarkan Tabel 1 dapat diketahui bahwa persentase liat pada lahan tersebut yaitu $51 \%-59 \%$. Hal ini sesuai dengan pendapat Hardjowigeno (2003) yang menyatakan bahwa tanah disebut bertekstur liat jika liatnya $>35 \%$ kemampuan menyimpan air tinggi.

Berdasarkan pada Tabel 1 terdapat 3 titik pengambilan sampel yaitu pada sampel titik 1 berada pada lintasan pertama, sampel titik 2 berada pada lintasan ke-empat, dan sampel titik 3 berada pada lintasan yang berada hampir ditengah lahan persawahan. Perbedaan titik pengambilan sampel saat pembelokan tersebut guna untuk mengetahui perbedaan tekstur tanah, kadar air dan bulk density pada bagian pinggir lahan dan bagian tengah lahan. Berdasarkan hasil analisis di laboratorium menunjukkan bahwa klas tekstur pada 3 titik sampel tersebut termasuk dalam klas tekstur liat sementara nilai kadar air dan bulk density yang berbeda-beda. 


\section{Pengaruh Roda Sebelah Dalam dan Luar Terhadap Kadar Air}

Pada penelitian ini dilakukan pengambilan sampel pada kedalaman 0-10 $\mathrm{cm}$ dan 10-20 cm. Pengambilan sampel pada kedalaman $0-10 \mathrm{~cm}$ diperoleh persentase kadar air yang lebih kecil dibandingkan sampel pada kedalaman 10-20 cm. Dapat dilihat pada gambar 3 dan 4 bahwa semakin dalam suatu lapisan tanah maka semakin besar pula persentase kadar airnya. Lintasan combine harvester pada saat setelah pengoperasian mengalami nilai bulk density yang meningkat, hal ini disebabkan tanah mengalami pemadatan karena air dan pori tanah terdesak keluar akibat tekanan oleh roda. Hal ini sesuai dengan pendapat Hanafiah (2005) yang menyatakan bahwa apabila tanah memiliki tingkat kadar air yang tinggi maka bulk density dan partikel density akan rendah begitupun sebaliknya.

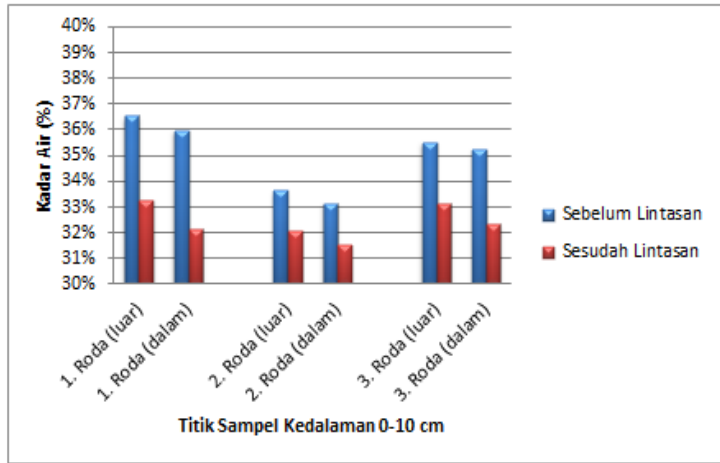

Gambar 3. Grafik perbandingan nilai kadar air sebelum dan sesudah lintasan pada kedalaman 0-10 cm

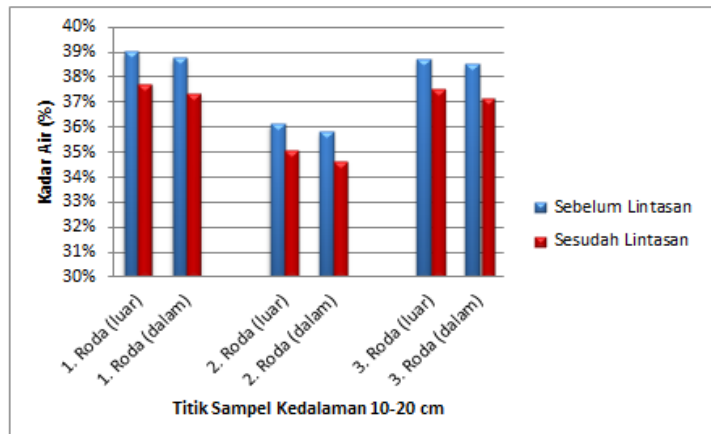

Gambar 4. Grafik perbandingan nilai kadar air sebelum dan sesudah lintasan pada kedalaman 10-20 cm

Berdasarkan hasil analisis menunjukkan bahwa akibat dari tekanan yang disebabkan oleh lintasan roda combine harvester mengakibatkan terjadinya penurunan persentase kadar air tanah pada setiap kedalaman. Pada gambar 3 dan 4 dapat diketahui bahwa persentase kadar air sebelum lintasan lebih besar dibandingkan persentase kadar air sesudah lintasan. Hal ini disebabkan persentase kadar air akan mengalami penurunan ketika mendapatkan tekanan dari roda combine harvester pada saat proses pengoperasian. Pada kedalaman $0-10 \mathrm{~cm}$ saat setelah dilintasi combine harvester mengalami penurunan persentase kadar air tertinggi terjadi pada sampel 1 yaitu $8,96 \%$ pada roda sebelah luar dan $10,65 \%$ pada roda sebelah dalam. Penurunan terendah terjadi pada sampel 2 yaitu $4,55 \%$ pada roda sebelah luar dan 4,93\% pada roda sebelah dalam. Pada kedalaman 10-20 cm penurunan persentase kadar air tertinggi terjadi pada sampel 1 yaitu 3,27\% pada roda sebelah luar dan 3,61\% pada roda sebelah dalam. Penurunan terendah terjadi pada sampel 2 yaitu $2,88 \%$ pada roda sebelah luar dan 3,23\% pada roda sebelah dalam. Berdasarkan data tersebut maka dapat disimpulkan bahwa tekanan pada roda sebelah dalam dan sebelah luar mengalami perbedaan, penurunan persentase kadar air pada roda sebelah dalam lebih besar dibandingkan pada roda sebelah luar. Hal ini disebabkan karena combine harvester pada saat beroperasi berputar pada arah kanan maka titik kuat alat cenderung pada roda sebelah dalam.

\section{Pengaruh Roda Sebelah Dalam dan Luar Terhadap Bulk Density}

Nilai Bulk density menunjukkan perbandingan antara berat tanah kering dengan volume tanah termasuk volume pori-pori tanah. Bulk density merupakan petunjuk kepadatan tanah. Makin padat suatu tanah makin tinggi bulk density. Beban yang ringan pada mesin hanya menyebabkan pemadatan di permukaan tanah, sedangkan beban yang berat dapat menyebabkan pemadatan yang lebih dalam. Hal ini sesuai dengan pendapat Kusuma (1998) yang menyatakan bahwa secara umum nilai bulk density tanah setelah mendapat perlakuan 
lintasan memperlihatkan nilai yang meningkat sejalan dengan penambahan jumlah lintasan pada tiap kedalaman.

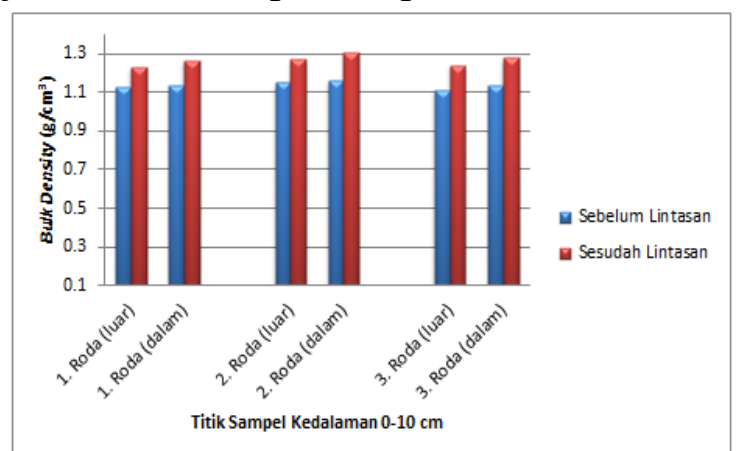

Gambar 5. Grafik perbandingan nilai bulk density sebelum dan sesudah lintasan kedalaman 0-10 cm

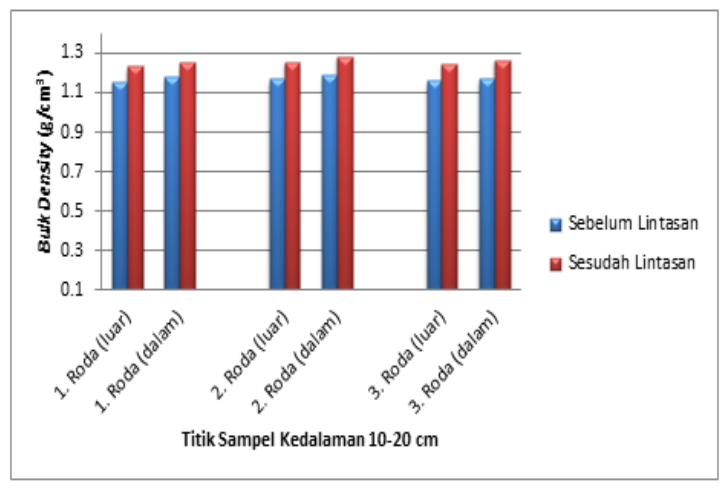

Gambar 6. Grafik perbandingan nilai bulk density sebelum dan sesudah lintasan kedalaman 10-20 cm

Berdasarkan hasil analisis dapat dilihat pada Gambar 5 dan 6 yang menunjukkan bahwa pada kedalaman $0-10 \mathrm{~cm}$ saat setelah dilintasi combine harvester mengalami kenaikan nilai bulk density. Persentase kenaikan bulk density tertinggi terjadi pada sampel 2 yaitu $10,41 \%$ pada roda sebelah luar dan $12,44 \%$ pada roda sebelah dalam. Kenaikan nilai bulk density yang terendah terjadi pada sampel 1 yaitu 9,23\% pada roda sebelah luar dan 11,34\% pada roda sebelah dalam. Sedangkan pada kedalaman 10-20 $\mathrm{cm}$ kenaikan nilai bulk density yang tertinggi terjadi pada sampel 2 yaitu $7,42 \%$ pada roda sebelah luar dan $8,17 \%$ pada roda sebelah dalam. Kenaikan nilai bulk density yang terendah terjadi pada sampel 1 yaitu $6,93 \%$ pada roda sebelah luar dan $6,05 \%$ pada roda sebelah dalam. Berdasarkan data tersebut maka dapat disimpulkan bahwa persentase kenaikan nilai bulk density pada roda sebelah dalam lebih besar dibandingkan pada roda sebelah luar. Karena lintasan pada saat pembelokan memberikan pengaruh pada nilai bulk density, dimana semakin meningkat proses lintasan pembelokan combine harvester maka nilai bulk density yang dihasilkan juga meningkat. Begitupun sebaliknya jika lintasan hanya satu kali maka tidak terlalu berpengaruh terhadap nilai bulk density yang dihasilkan. Hal ini disebabkan pada saat proses pembelokan combine harvester membutuhkan waktu beberapa kali melintas maju dan mundur agar alat tersebut bisa kembali dalam keadaan lurus.

\section{Pengaruh Roda Sebelah Dalam dan Luar Terhadap Porositas Tanah}

Berdasarkan hasil penelitian menunjukkan bahwa porositas tanah sebelum lintasan lebih besar dibandingkan porositas tanah setelah lintasan. Hal ini disebabkan karena pori-pori tanah pada saat sebelum lintasan berukuran besar yang mengakibatkan air akan mudah masuk ke dalam tanah dan begitupun sebaliknya poripori saat setelah lintasan berukuran kecil ini dikarenakan telah terjadinya proses pemadatan akibat lintasan roda combine harvester yang mengakibatkan pori-pori tanah menjadi kecil sehingga air akan sulit masuk ke dalam tanah. Hal ini sesuai dengan pendapat Madjid (2010) yang menyatakan bahwa kapasitas pegang air tanah umumya berada pada keadaan optimum pada saat pori-pori tanah berukuran besar. Porositas tanah sangat berpengaruh terhadap ketersediaan air tanah. Apabila tanah memiliki porositas yang tinggi maka air akan mudah masuk ke dalam tanah, akibatnya kapasitas pegang tanah juga meningkat.

Berdasarkan hasil analisis, gambar 7 dan 8 menunjukkan bahwa nilai porositas yang dihasilkan mencapai $60 \%$ dan termasuk dalam struktur yang baik. Hal ini sesuai dengan pendapat Utami (2009) yang menyatakan bahwa porositas dipengaruhi oleh ukuran partikel dan struktur. Tanah berpasir mempunyai porositas rendah (40\%) dan tanah lempung hingga liat mempunyai 
porositas yang tinggi, jika strukturnya baik dapat mencapai porositas $60 \%$.

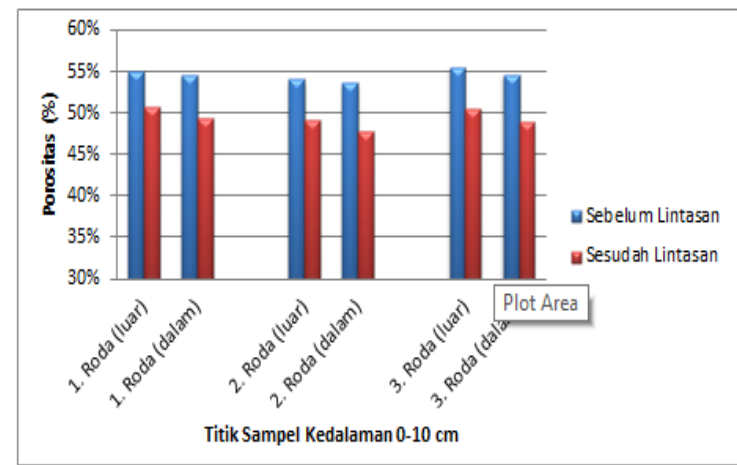

Gambar 7. Grafik nilai Porositas sebelum dan sesudah lintasan pada kedalaman $0-10 \mathrm{~cm}$

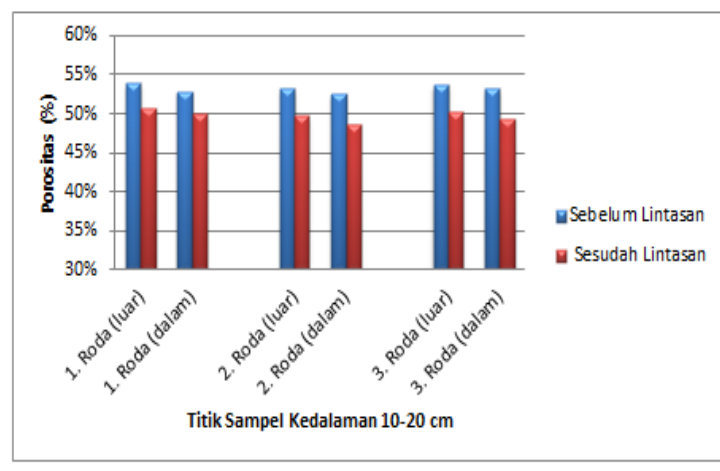

Gambar 8. Grafik nilai Porositas sebelum dan sesudah lintasan pada kedalaman $10-20 \mathrm{~cm}$

\section{Pengaruh Kecepatan Roda Sebelah Dalam Dan Sebelah Luar Terhadap Pemadatan Tanah}

Menurut Harianja (2016), menyatakan bahwa setiap benda yang bergerak pasti memiliki kecepatan. Kecepatan gerak benda ini dihitung dengan cara membandingkan panjang lintasan yang ditempuh oleh benda yang bergerak dalam waktu yang dihabiskan dalam proses gerak tersebut. Berikut data perhitungan kecepatan combine harvester pada saat pembelokan.

Tabel 2. Perhitungan kecepatan combine harvester pada saat pembelokan

\begin{tabular}{clcccc}
\hline No & $\begin{array}{c}\text { Titik } \\
\text { Sampel }\end{array}$ & $\begin{array}{c}\text { Waktu } \\
(\mathbf{s})\end{array}$ & $\begin{array}{c}\text { Jarak } \\
(\mathbf{m})\end{array}$ & $\begin{array}{c}\text { Kecp } \\
(\mathbf{m} / \mathbf{s})\end{array}$ & $\begin{array}{c}\text { BD } \\
\left(\mathbf{g} / \mathbf{c m}^{\mathbf{3}}\right)\end{array}$ \\
\hline \multirow{2}{*}{1} & $\begin{array}{l}\text { Roda } \\
\text { Luar }\end{array}$ & 17 & 4.5 & 0.26 & 1.231 \\
& $\begin{array}{l}\text { Roda } \\
\text { dalam }\end{array}$ & 17 & 3.4 & 0.20 & 1.264
\end{tabular}

\begin{tabular}{clcccc}
\hline No & $\begin{array}{c}\text { Titik } \\
\text { Sampel }\end{array}$ & $\begin{array}{c}\text { Waktu } \\
(\mathbf{s})\end{array}$ & $\begin{array}{c}\text { Jarak } \\
(\mathbf{m})\end{array}$ & $\begin{array}{c}\text { Kecp } \\
(\mathbf{m} / \mathbf{s})\end{array}$ & $\begin{array}{c}\text { BD } \\
\left(\mathbf{g} / \mathbf{c m}^{\mathbf{3}}\right)\end{array}$ \\
\hline 2 & $\begin{array}{l}\text { Roda } \\
\text { Luar }\end{array}$ & 20 & 4.1 & 0.21 & 1.269 \\
& $\begin{array}{l}\text { Roda } \\
\text { dalam }\end{array}$ & 20 & 3.1 & 0.16 & 1.306 \\
3 & $\begin{array}{l}\text { Roda } \\
\text { Luar } \\
\text { Roda } \\
\text { dalam }\end{array}$ & 19 & 4.3 & 0.23 & 1.240 \\
& 19 & 3.2 & 0.17 & 1.277 \\
\hline
\end{tabular}

Berdasarkan hasil perhitungan pada Tabel 2 menunjukkan bahwa jarak tempuh pada roda sebelah luar lebih jauh dibandingkan pada roda sebelah dalam, sehingga kecepatan pada roda sebelah dalam lebih kecil dibandingkan pada roda sebelah luar. Hal ini disebabkan combine harvester berputar pada arah kanan maka titik kuat alat cenderung pada roda sebelah dalam. Hal ini sesuai dengan pendapat Harianja (2016) yang menyatakan bahwa jika nilai jarak (s) besar dan nilai waktu (t) kecil maka benda bergerak dalam kecepatan yang tinggi, begitu juga sebaliknya jika nilai jarak (s) kecil dalam waktu yang besar maka benda bergerak dalam keadaan yang sangat lambat.

Berdasarkan data kecepatan yang telah didapatkan maka dapat dihubungkan dengan besar nilai bulk density setelah dilintasi combine harvester pada kedalaman 0-10 cm yaitu sampel 1 pada roda sebelah luar dengan kecepatan $0,26 \mathrm{~m} / \mathrm{s}$ sehingga bulk density yang didapatkan yaitu $1,231 \mathrm{~g} / \mathrm{cm}^{3}$. Pada roda sebelah dalam dengan kecepatan $0,20 \mathrm{~m} / \mathrm{s}$ sehingga bulk density yang didapatkan yaitu $1,264 \mathrm{~g} / \mathrm{cm}^{3}$. Sampel 2 pada roda sebelah luar dengan kecepatan $0,21 \mathrm{~m} / \mathrm{s}$ sehingga bulk density yang didapatkan yaitu $1,269 \mathrm{~g} / \mathrm{cm}^{3}$. Pada roda sebelah dalam dengan kecepatan $0,16 \mathrm{~m} / \mathrm{s}$ sehingga bulk density yang didapatkan yaitu $1,306 \mathrm{~g} / \mathrm{cm}^{3}$. Sampel 3 pada roda sebelah luar dengan kecepatan $0,23 \mathrm{~m} / \mathrm{s}$ sehingga bulk density yang didapatkan yaitu 1,240 $\mathrm{g} / \mathrm{cm}^{3}$. Pada roda sebelah dalam dengan kecepatan $0,17 \mathrm{~m} / \mathrm{s}$ sehingga bulk density yang didapatkan yaitu $1,277 \mathrm{~g} / \mathrm{cm}^{3}$. 


\section{KESIMPULAN}

Berdasarkan penelitian yang telah dilaksanakan maka dapat diperoleh kesimpulan sebagai berikut :

1. Penggunaan combine harvester pada proses pemanenan mengakibatkan pemadatan yang lebih besar pada roda sebelah dalam dibandingkan pada roda sebelah luar.

2. Kecepatan combine harvester yang kecil pada saat pembelokan mengakibatkan nilai bulk density besar. Sedangkan kecepatan yang tinggi mengakibatkan nilai bulk density yang sedikit.

\section{DAFTAR PUSTAKA}

Hanafiah, Kiemas Ali. 2005. Dasar-dasar Ilmu Tanah. PT. Rajagrafindo Persada: Jakarta.

Hardjowigeno, S. 2003. Ilmu Tanah. PT. Mediyatama Sarana Perkasa: Jakarta.

Hardjowigeno, S. 2007. Ilmu Tanah. Akademika Pressindo: Jakarta.

Harianja, Uniks. 2016. Gerak Benda, Kecepatan dan Percepatan. Informatika Elektronika Komputer: Jakarta.

Katalog LKPP, 2017. Combine Harvester KUBOTA DC-60. Bina Pertiwi: Jakarta.

Kusuma. 1998. Pengaruh Pemberian Bahan Organik dan lintasan Traktor Terhadap Pemadatan Tanah. Fakultas Teknologi Pertanian. Institut Pertanian Bogor: Bogor.

Madjid. 2010. Sifat dan Ciri Tanah. Fakultas Pertanian. Institut Pertanian Bogor: Bogor.

Utami, Nur Hikmah. 2009. Kajian Sifat Fisik, Sifat Kimia dan Sifat Biologi Tanah Paska Tambang Galian C pada Tiga Penutupan Lahan. Institut Pertanian Bogor: Bogor. 